\title{
Company Characteristics, Disability Inclusion Practices, and Employment of People with Disabilities in the Post COVID-19 Job Economy: A Cross Sectional Survey Study
}

\author{
Fong Chan ${ }^{1} \cdot$ Timothy N. Tansey $^{1} \cdot$ Kanako Iwanaga $^{2}$ (D) Jill Bezyak ${ }^{3} \cdot$ Paul Wehman $^{4} \cdot$ Brian N. Phillips $^{5}$. \\ David R. Strauser ${ }^{6}$. Catherine Anderson ${ }^{7}$
}

Accepted: 23 October 2020 / Published online: 2 November 2020

(c) Springer Science+Business Media, LLC, part of Springer Nature 2020

\begin{abstract}
Purpose In the post coronavirus disease 2019 (COVID-19) recession economy, rehabilitation counselors, transition specialists, and other disability service providers must redouble their efforts to connect with employers to create employment opportunities for people with physical and mental impairments. The purpose of the present study was to investigate company characteristics and effective disability inclusion practices that are related to employment of people with disabilities. Methods Four hundred sixty-six employers completed a demographic questionnaire and the Disability Inclusion Profiler. Results Results indicated company characteristics and disability practices were positively related to employment of people with disabilities. Conclusions Findings of the present study can be used by transition specialists, rehabilitation counselors, and other disability service providers to engage and connect with employers to increase employment opportunity for people with disabilities in the post COVID-19 economy. Future research and practice implications are provided.
\end{abstract}

Keywords Diversity $\cdot$ Inclusion $\cdot$ Disability $\cdot$ Employment $\cdot$ Vocational rehabilitation $\cdot$ Recession $\cdot$ COVID-19

Kanako Iwanaga

iwanagak@vcu.edu

1 Department of Rehabilitation Psychology and Special Education, University of Wisconsin-Madison, Madison, USA

2 Department of Rehabilitation Counseling, College of Health Professions, Virginia Commonwealth University, 900 East Leigh Street, Richmond, VA 23298-0330, USA

3 Department of Rehabilitation Counseling and Sciences, University of Northern Colorado, Greeley, USA

4 Virginia Commonwealth University- Rehabilitation Research and Training Center, Virginia Commonwealth University, Richmond, USA

5 Department of Special Education and Rehabilitation Counseling, College of Education and Human Services, Utah State University, Logan, USA

6 Department of Kinesiology and Community Health, University of Illinois at Urbana-Champaign, Champaign, USA

7 Stout Vocational Rehabilitation Institute, University of Wisconsin-Stout, Stout, USA

\section{Introduction}

Gainful employment has many known financial, psychological, social, and health benefits [1-5]. Suitable employment enables working-age adults to provide for themselves, access health care, connect with people, and contribute as a productive member of society [1]. Work identity (the meaning of people's jobs and its relationship to their sense of being) is a predominant part of people's self-identity and a requisite component of living a meaningful and fulfilled life [6]. Research has indicated that persons who are gainfully employed have better physical and mental health than those who are unemployed [3, 7]. Conversely, unemployment, income inequality, and poverty are associated with poor physical and mental health, low self-esteem, and lower levels of life satisfaction, due to the loss of income, lack of access to health care, stigma, social isolation, and psychological distress [8-10].

Individuals with disabilities are one of the most stigmatized and marginalized groups in the world [11-13], which results in inequities in employment, as outlined above. During the Great Recession (i.e., the collapse of the financial system that spans the period from December 2007 through 
September 2009 for a total duration of 22 months), among prime working-age adults (25-54 years old), the unemployment rate of people with disabilities ranged from 2.0 to 2.3 times that of people without disabilities [14]. In the middle of 2019, when the United States economy was approaching full employment [15], many marginalized groups benefited from the robust economy and returned to the labor force in droves [16], with the exception of people with disabilities. Despite the high demand for workers in 2019, employers were not hiring large numbers of people with disabilities [17].

As a result of the coronavirus disease 2019 (COVID-19) pandemic, the United States economy is entering another recession [18]. In September 2020, the employment-topopulation ratio of $28.3 \%$ for working-age individuals with disabilities is significantly lower than the $70.0 \%$ rate for working-age people without disabilities [19]. The unemployment rate for people with disabilities was $12.5 \%$ also higher than the $7.5 \%$ rate for people without disabilities [20]. In the post COVID-19 job economy, similar to the Great Recession, excess labor supply will significantly affect individuals with disabilities' ability to find or retain employment. As such, working-age adults with disabilities are vulnerable to the debilitating consequences of unemployment and poverty. To be effective in assisting people with disabilities find and retain employment in a grim economy, it is imperative to carefully review the employer practices literature for studies conducted before or after the Great Recession. Lessons learned from these research studies can help transition specialists, rehabilitation counselors and other disability service providers better understand the impact of company characteristics, employment policies, and disability inclusion practices on hiring and retaining people with disabilities in strong and weak economies.

Gilbride et al. [21] conducted a qualitative research study to examine characteristics of work environments and employers who are open to hiring and accommodating people with disabilities. They found that normative belief (i.e., commitments at the leadership/executive level that trickle down to all levels of the organization), diversity and disability inclusion policies and procedures, a strong focus on ability not disability, and knowledge and experience providing job accommodation and workplace supports characterized companies that are committed to hiring and supporting people with disabilities in their workforces. Chan and colleagues [22] collected more evidence on this topic by conducting a survey of employers in the Midwest and found that including disability in the organization's diversity and inclusion policy and knowledge of the Americans with Disabilities Act (ADA) and job accommodations were the most significant predictors of inclusion of people with disabilities in the workplace. Their findings are consistent with findings reported by Habeck et al. [23] who reported that having an in-house disability management program and inclusion of disability in companies' diversity and inclusion policies and procedures would lead to hiring and retaining people with disabilities.

Bezyak et al. [24] examined seven disability inclusion strategies (i.e., internship program, trial employment, special interviewing process, for-profit job placement, disability inclusion and diversity policies and procedures, and working with state vocational rehabilitation agencies) in a sample of employers in Colorado. Results indicated all disability inclusion strategies in their study were positively related to hiring intention. Iwanaga and colleagues [25] reported that disability inclusion training is related to inclusion of people with disabilities in the workplace. Fraser et al. [26, 27] also conducted a focus group study and a quantitative study using the Theory of Planned Behavior as their research framework. They found that company climate related to disability inclusion is influenced by normative beliefs of management or senior executives and whether they support or hinder the hiring of people with disabilities.

\section{Rationale for and Purpose of the Study}

In the post COVID-19 job economy, it will be more difficult to help persons with disabilities find and maintain gainful employment. Rehabilitation counselors, transition specialist, and disability service providers must make greater efforts to create employment opportunities for their clients. It is essential for leadership, managers, and counselors in state vocational rehabilitation agencies to focus on the local job economy, engage employers to identify their needs for specifically trained and skilled workers, and cooperate with local employers and educational institutions to provide customized training to people with disabilities to meet employer demands for skilled workers. There is an urgent need to identify characteristics of companies and disability inclusion practices that will lead to employment of people with disabilities especially during a recession. As a result, the purpose of the present study was to investigate company characteristics and effective disability inclusion practices that are related to employment of people with disabilities in the workplace. Findings from this study can provide a roadmap for state vocational rehabilitation agencies and community-based rehabilitation and health organizations to engage and connect with companies that are committed to hiring people with disabilities. The following research questions were investigated:

RQ1 What is the relationship between disability inclusion practices and employment participation of people with disabilities in the workplace? 
RQ2 Do company characteristics and disability inclusion practices affect the employment rates of people with disabilities in the workplace?

\section{Method}

\section{Design}

A cross-section survey design was used for the present study. Institutional Review Board (IRB) approval for this study was obtained from the University of Wisconsin-Madison.

\section{Participants}

Participants in this study included 466 human resources managers and professionals who made hiring decisions within their companies. The Organization for Economic Co-operation and Development (OECD) classification was used to designate company size [28]. The majority of participants were employees of large size companies (greater than or equal to 250 employees; $48.7 \%$ ), followed by medium size companies (between 50 and 249 employees; 29.1\%) and small size companies (less than 50 employees; 22.2\%). A range of industry types were represented, including Professional, Scientific, and Technical Services (21.0\%); Health Care and Social Assistance (17.0\%); Accommodation, Food services and Retail Trade (12.8\%); Information Technology (8.4\%); Finance and Insurance (7.7\%), and Educational Services (7.7\%). Over half (47.2\%) of the participants' companies have Federal contracts over $\$ 50,000$, and $27.0 \%$ were Fortune 500 companies. Only $9.2 \%$ of the participants' companies had more than $7 \%$ of employees with self-identified disabilities, while $90.8 \%$ of the participants indicated their companies had less than $7 \%$ of employees with disabilities in their workforces. Twenty percent of the participants indicated their companies did not have any employees with selfidentified disabilities.

\section{Measures}

\section{Company Characteristics}

Company characteristics of interest for the current study include company size, Fortune 500 companies, and Federal contractors. In the present study, the Organization for Economic Co-operation and Development's (OECD) definition for company size was used, which classifies small companies as having 10 to 49 employees, medium-sized companies as having 50 to 249 employees, and large-sized companies as those with 250 or more employees [28]. Fortune 500 is an annual list compiled and published by the Fortune magazine that ranks 500 of the largest United States corporations by total revenue for their respective fiscal year [29]. Lastly, Federal contractor is defined by Sect. 503 of the Rehabilitation Act as companies with Federal contracts of $\$ 50,000$ or more [30]. Participants provided all this information as part of the demographic questionnaire.

\section{Disability Inclusion}

Disability inclusion practices was assessed using the Disability Inclusion Profiler (DIP; [31]). This measure was developed based on the standard test development process recommended by Crocker and Algina [32]. The test specifications, the a priori categories, and items for the a priori categories were developed based on a comprehensive review of the demand-side employment literature, a focus group and a Delphi study with employers to identify effective disability inclusion practices. The final measure comprised 34 items and six a priori categories: (a) disability inclusion commitment, (b) disability inclusion policies and procedures, (c) disability inclusion preparedness, (d) disability inclusion resources, (e) disability inclusion strategies, and (f) disability inclusion attitudes. Each item was rated on a 4-point Likert importance rating scale $(1=$ Not important, $2=$ Somewhat important, $3=$ Important, $4=$ Very important $)$ and a 4-point Likert implementation scale $(1=$ Not currently in implementation, $2=$ In planning for implementation, $3=$ Partial implementation, $4=$ Full implementation). In the present study, the internal consistency reliability coefficients (Cronbach's alpha) were 0.96 for the importance scale, 0.96 for the implementation scale, and 0.88 for the weighted implementation scale.

\section{Utilization Rate}

Percent of people with disabilities in the company's workforce was used as an external correlate to identify effective disability inclusion practices in the Disability Inclusion Profiler. Participants were asked to indicate the percent of individuals with self-identified disabilities in their workforce based on half percent increments, results ranged from $0 \%$ to greater than $7 \%$. The mean utilization rate in this sample was $2.75 \%(S D=2.27 \%)$.

\section{Procedures}

Amazon Mechanical Turk (MTurk) and TurkPrime was used to collect data for the present study. MTurk has been used by thousands of researchers to obtain sample participants while TurkPrime provides a more user-friendly interface and additional options for data collection [33, 34]. The TurkPrime panel was used to recruit the target population (i.e., HR managers or project managers with hiring authority). These panels, or subgroups, are created from the millions of survey 
responders affiliated with MTurk and TurkPrime. The Disability Inclusion Profiler takes about 15 minutes to complete, and participants received a $\$ 10$ gift card for completing the questionnaire.

\section{Data Analysis}

The Statistical Package for the Social Sciences (SPSS 25.0) was used to analyze data for the present study. Descriptive statistics were computed to provide information related to the demographic characteristics of the participants; correlational analyses were computed to evaluate the relationships between disability inclusion practices and employment rates of people with disabilities in the workplace; and three analysis of variance (ANOVAs) were computed to compare utilization rates of people with disabilities based on company characteristics. For ease of interpretation, we have converted the weighted implementation total scores to T-scores with a mean of 50 and a standard deviation of 10 .

\section{Results}

In the present study, human resources managers and professionals who made hiring decisions were asked to rate the importance and stages of implementation of 34 disability inclusion practices identified in the Disability Inclusion Profiler. Means and standard deviations of the importance, implementation, and weighted implementation scores for the disability inclusion practices, along with the correlations between these practices and employment of people with disabilities in their workplace are presented in Table 1.

\section{Disability Inclusion Practices and Employment of People with Disabilities}

As indicated in Table 1, there are 10 disability inclusion practices that are significantly associated with employment rates of people with disabilities in the workplace (Pearson correlation coefficients between 0.20 and 0.26 , $p<.001$; close to a medium effect size; [35]), which represent the commitment of leadership/executive management in the organizations to support the inclusion of people with disabilities:

- Have an accommodations budget line item to cover costs of accommodations for employees.

- Participate in job fairs for people with disabilities.

- Have annual targets and assess performance to achieve application and employment goals of persons with disabilities.
- Have in-house (or contractual) disability management personnel that are responsible for handling issues related to the ADA and job accommodations.

- Have a hiring manager with a disability.

- Senior leadership clearly communicates its commitment to employment of people with disabilities.

- Post statement of commitment to hiring people with disabilities on the company website.

- Have a senior executive with a disability.

- Provide disability inclusion training for company's HR recruiters.

- Have a mechanism to assess the number of people with disabilities in the company.

There are 13 disability inclusion practices with Pearson correlation coefficients between 0.10 and $0.19(p<.01)$, with an emphasis on implementing disability inclusion policies and procedures by mid-level managers, supervisors, and staff:

- Report progress toward hiring persons with disabilities to senior management.

- Have internship and summer employment programs directed toward high school and college students with disabilities.

- Identify and select partners that can be valuable in recruiting qualified individuals with disabilities.

- Include "work and disability" as a topic in the company's diversity and inclusion training.

- Have internal and external resources to support the goals of the company's disability employment and inclusion program.

- Have a mentoring program to promote advancement of diverse persons.

- Communicate emergency preparedness policy or procedures with specific mention of persons with disabilities.

- Have strategies to attract qualified applications from persons with disabilities.

- Include disability in the company's diversity and inclusion policies and procedures.

- Senior leadership communicates clearly and affirmatively the company's commitment to recruit and hire people with disabilities.

- Have contracts with employment agencies.

- Have a disability accommodation policy.

- Include "work and disability" as a topic in the company's new employee orientation training.

- Offer an Employee Assistance Program.

- Have process to assess website for compliance of coding with existing law and regulations.

- Have policy to make all job interview candidates aware of the option to request accommodations for the interview. 
Table 1 Relationship between disability inclusion practices and employment of people with disabilities in the workplace

\begin{tabular}{|c|c|c|c|c|c|}
\hline Disability inclusion practice & $\begin{array}{l}\text { Importance } \\
\text { score } M \\
(S D)\end{array}$ & SOC score $^{\mathrm{a}} M(S D)$ & $\begin{array}{l}\text { Relative impor- } \\
\text { tance score } M \\
(S D)\end{array}$ & $\begin{array}{l}\text { Weighted } \\
\text { SOC score } M \\
(S D)\end{array}$ & Pearson $r^{b}$ \\
\hline $\begin{array}{l}\text { 1. Include disability in the company's diversity and inclu- } \\
\text { sion policies and procedures }\end{array}$ & $3.32(0.83)$ & $3.21(0.96)$ & $0.032(0.008)$ & $0.105(0.042)$ & $.17 * * *$ \\
\hline $\begin{array}{l}\text { 2. Post statement of commitment to hiring people with dis- } \\
\text { abilities on company website }\end{array}$ & $3.21(0.88)$ & $3.00(1.09)$ & $0.031(0.007)$ & $0.095(0.042)$ & $.22 * * *$ \\
\hline $\begin{array}{l}\text { 3. Have stay-at-work and return-to-work retention policies } \\
\text { and procedures }\end{array}$ & $3.21(0.90)$ & $3.04(1.05)$ & $0.031(0.009)$ & $0.098(0.048)$ & .06 \\
\hline $\begin{array}{l}\text { 4. Include "work and disability" as a topic in the company's } \\
\text { diversity and inclusion training }\end{array}$ & $3.19(0.87)$ & $3.07(1.03)$ & $0.031(0.007)$ & $0.096(0.039)$ & $.19 * * *$ \\
\hline $\begin{array}{l}\text { 5. Include "work and disability" as a topic in the company's } \\
\text { new employee orientation training }\end{array}$ & $3.16(0.92)$ & $2.98(1.09)$ & $0.030(0.007)$ & $0.093(0.042)$ & $.15^{* *}$ \\
\hline $\begin{array}{l}\text { 6. Have strategies to attract qualified applications from } \\
\text { persons with disabilities - Importance }\end{array}$ & $3.05(0.95)$ & $2.75(1.12)$ & $0.029(0.008)$ & $0.083(0.041)$ & $.18^{* * *}$ \\
\hline $\begin{array}{l}\text { 7. Have internship and summer employment programs } \\
\text { directed toward high school and college students with } \\
\text { disabilities }\end{array}$ & $2.81(1.06)$ & $2.35(1.19)$ & $0.027(0.008)$ & $0.067(0.043)$ & $.19 * * *$ \\
\hline 8. Participate in job fairs for people with disabilities & $2.91(0.98)$ & $2.53(1.24)$ & $0.028(0.007)$ & $0.074(0.044)$ & $.25 * * *$ \\
\hline $\begin{array}{l}\text { 9. Have in-house (or contractual) disability management } \\
\text { personnel that are responsible for handling issues related } \\
\text { to the ADA and job accommodations }\end{array}$ & $3.08(0.99)$ & $2.77(1.19)$ & $0.029(0.008)$ & $0.085(0.045)$ & $.23 * * *$ \\
\hline $\begin{array}{l}\text { 10. Senior leadership communicates clearly and affirma- } \\
\text { tively the company's commitment to recruit and hire } \\
\text { people with disabilities }\end{array}$ & $3.09(0.90)$ & $2.79(1.12)$ & $0.030(0.007)$ & $0.084(0.040)$ & $.17 * * *$ \\
\hline $\begin{array}{l}\text { 11. Identify and select partners that can be valuable in } \\
\text { recruiting qualified individuals with disabilities }\end{array}$ & $2.99(0.97)$ & $2.63(1.16)$ & $0.028(0.007)$ & $0.078(0.042)$ & $.19 * * *$ \\
\hline $\begin{array}{l}\text { 12. Have internal and external resources to support the } \\
\text { goals of the company's disability employment and inclu- } \\
\text { sion program }\end{array}$ & $3.08(0.94)$ & $2.75(1.15)$ & $0.029(0.007)$ & $0.083(0.042)$ & $.19 * * *$ \\
\hline $\begin{array}{l}\text { 13. Have annual targets and assess performance to achieve } \\
\text { application and employment goals of persons with dis- } \\
\text { abilities }\end{array}$ & $2.94(0.99)$ & $2.57(1.18)$ & $0.028(0.007)$ & $0.075(0.042)$ & $.24 * * *$ \\
\hline 14. Have a senior executive with a disability & $2.11(1.07)$ & $1.97(1.20)$ & $0.020(0.009)$ & $0.045(0.040)$ & $.22 * * *$ \\
\hline 15. Have a hiring manager with a disability & $2.19(1.08)$ & $2.08(1.23)$ & $0.021(0.009)$ & $0.050(0.043)$ & $.22 * * *$ \\
\hline $\begin{array}{l}\text { 16. Emergency preparedness policy or procedures in place } \\
\text { with specific mention of persons with disabilities }\end{array}$ & $3.23(0.94)$ & $2.89(1.19)$ & $0.031(0.008)$ & $0.092(0.046)$ & $.10 *$ \\
\hline $\begin{array}{l}\text { 17. Report progress toward hiring persons with disabilities } \\
\text { to senior management }\end{array}$ & $2.74(1.03)$ & $2.52(1.18)$ & $0.026(0.008)$ & $0.070(0.043)$ & $.19 * * *$ \\
\hline $\begin{array}{l}\text { 18. Communicate emergency preparedness policy or proce- } \\
\text { dures with specific mention of persons with disabilities }\end{array}$ & $3.09(0.97)$ & $2.84(1.19)$ & $0.030(0.007)$ & $0.087(0.045)$ & $.18^{* * *}$ \\
\hline $\begin{array}{l}\text { 19. Have process to assess website for compliance of cod- } \\
\text { ing with existing law and regulations }\end{array}$ & $3.16(0.93)$ & $2.95(1.17)$ & $0.030(0.008)$ & $0.093(0.046)$ & $.13 * *$ \\
\hline 20. Offer an Employee Assistance program & $3.27(0.91)$ & $3.15(1.11)$ & $0.032(0.007)$ & $0.102(0.045)$ & $.13 * *$ \\
\hline 21. Offer a health and wellness program to employees & $3.36(0.87)$ & $3.20(1.09)$ & $0.033(0.008)$ & $0.107(0.046)$ & .03 \\
\hline 22. Offer health care coverage to employees & $3.62(0.73)$ & $3.46(0.97)$ & $0.036(0.010)$ & $0.126(0.051)$ & $-.10^{*}$ \\
\hline $\begin{array}{l}\text { 23. Offer short-term disability benefits that are managed to } \\
\text { promote retention of people with disabilities in the work } \\
\text { force }\end{array}$ & $3.30(0.89)$ & $3.22(1.05)$ & $0.032(0.009)$ & $0.106(0.049)$ & .02 \\
\hline $\begin{array}{l}\text { 24. Display non-discrimination and/or equal opportunity } \\
\text { policy language that specifically mentions disability } \\
\text { on company external public-facing recruitment/career } \\
\text { website }\end{array}$ & $3.42(0.84)$ & $3.37(0.96)$ & $0.034(0.009)$ & $0.115(0.047)$ & -.04 \\
\hline $\begin{array}{l}\text { 25. Have policy to make all job interview candidates aware } \\
\text { of the option to request an accommodation(s) for the } \\
\text { interview }\end{array}$ & $3.21(0.92)$ & $3.07(1.11)$ & $0.031(0.008)$ & $0.097(0.045)$ & $.11 *$ \\
\hline 26. Have contracts with employment agencies & $2.71(1.13)$ & $2.69(1.24)$ & $0.026(0.010)$ & $0.077(0.049)$ & $.16^{* * *}$ \\
\hline
\end{tabular}


Table 1 (continued)

\begin{tabular}{|c|c|c|c|c|c|}
\hline Disability inclusion practice & $\begin{array}{l}\text { Importance } \\
\text { score } M \\
(S D)\end{array}$ & SOC score ${ }^{\mathrm{a}} M(S D)$ & $\begin{array}{l}\text { Relative impor- } \\
\text { tance score } M \\
(S D)\end{array}$ & $\begin{array}{l}\text { Weighted } \\
\text { SOC score } M \\
(S D)\end{array}$ & Pearson $r^{\mathrm{b}}$ \\
\hline 27. Have a disability accommodation policy & $3.28(0.91)$ & $3.17(1.09)$ & $0.032(0.008)$ & $0.103(0.044)$ & $.15^{* *}$ \\
\hline $\begin{array}{l}\text { 28. Have an accommodations budget line item to cover } \\
\text { costs of accommodations for employees }\end{array}$ & $2.96(0.99)$ & $2.75(1.17)$ & $0.028(0.007)$ & $0.080(0.042)$ & $.26 * * *$ \\
\hline $\begin{array}{l}\text { 29. Have a mechanism to assess the number of people with } \\
\text { disabilities in the company }\end{array}$ & $2.86(1.06)$ & $2.67(1.22)$ & $0.027(0.008)$ & $0.077(0.044)$ & $.20 * * *$ \\
\hline $\begin{array}{l}\text { 30. Have a mentoring program to promote advancement of } \\
\text { diverse persons }\end{array}$ & $3.02(0.98)$ & $2.58(1.21)$ & $0.029(0.007)$ & $0.091(0.039)$ & $.19 * * *$ \\
\hline 31. The workplace is accessible to people with disabilities & $3.35(0.97)$ & $3.30(1.02)$ & $0.033(0.010)$ & $0.113(0.054)$ & .02 \\
\hline $\begin{array}{l}\text { 32. The Sect. } 503 \text { Voluntary Self-Identification of Disabil- } \\
\text { ity Form has been implemented in the HR new employee } \\
\text { processing system }\end{array}$ & $3.23(1.03)$ & $3.14(1.10)$ & $0.031(0.010)$ & $0.104(0.053)$ & .05 \\
\hline $\begin{array}{l}\text { 33. Senior leadership clearly communicates its commitment } \\
\text { to meet the } 7 \% \text { utilization goal of people with disabilities. } \\
\text { - Importance }\end{array}$ & $2.78(1.12)$ & $2.69(1.15)$ & $0.027(0.009)$ & $0.078(0.047)$ & $.22 * * *$ \\
\hline $\begin{array}{l}\text { 34. Provide disability inclusion training for company's HR } \\
\text { recruiters }\end{array}$ & $3.04(1.11)$ & $2.93(1.15)$ & $0.029(0.010)$ & $0.092(0.051)$ & $.21 * * *$ \\
\hline
\end{tabular}

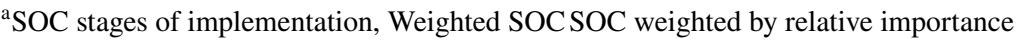

${ }^{\mathrm{b}}$ Correlation with utilization rate

$* p<.05 ; * * p<.01 ; * * * p<.001$

Table 2 Company size, implementation of disability inclusion practice, and utilization rate

\begin{tabular}{lllll}
\hline Outcome measure & $\begin{array}{l}\text { Small } \\
(M, S D)\end{array}$ & $\begin{array}{l}\text { Medium } \\
(M, S D)\end{array}$ & $\begin{array}{l}\text { Large } \\
(M, S D)\end{array}$ & $F(2,461)$ \\
\hline Implementation score & $44.26(12.22)$ & $50.78(8.92)$ & $52.16(8.45)$ & $24.87^{* * * *}$ \\
Utilization rate & $1.20 \%(1.93 \%)$ & $2.81 \%(2.19 \%)$ & $3.53 \%(2.28 \%)$ & $40.19 * * *$ \\
\hline
\end{tabular}

$* * * p<.001$

- Emergency preparedness policy or procedures in place with specific mention of persons with disabilities.

- Offer health care coverage to employees.

The total score for the disability inclusion practices was significantly associated with employment of people with disabilities in the workplace $(r=.32, p<.001$; medium effect size; [35]).

\section{Company Characteristics and Disability Inclusion Practices}

One-way analysis of variance (ANOVA) was performed to compare the effect of company sizes, Fortune $500 \mathrm{com}$ panies, and Federal contractors on implementation of disability inclusion practices. Means and standard deviations of the weighted implementation scores and utilization rates are presented in Tables 2, 3, and 4.
Table 3 Fortune 500 company, implementation of disability inclusion practice, and utilization rate

\begin{tabular}{llll}
\hline Outcome measure & $\begin{array}{l}\text { Non-fortune 500 } \\
M(S D)\end{array}$ & $\begin{array}{l}\text { Fortune } 500 \\
M(S D)\end{array}$ & $F(1,461)$ \\
\hline Implementation score & $48.96(10.61)$ & $52.58(7.59)$ & $12.24 * * *$ \\
Utilization rate & $2.34 \%(2.29 \%)$ & $4.04 \%(2.11 \%)$ & $52.55^{* * *}$ \\
\hline
\end{tabular}

$* * * p<.001$

\section{Company Size}

One-way ANOVA showed that the effect of company sizes on disability inclusion practices was significant, $F(2$, $461)=24.87, p<.001$. Post hoc analysis using the Tukey HSD test indicated that the mean implementation scores for large-size companies $(n=226 ; M=52.16, S D=8.45)$ and mid-size companies $(n=135 ; M=50.78, S D=8.92)$ were significantly higher than small-size companies $(n=103$; $M=44.26, S D=12.22$ ). However, there is no significant difference between large-size and mid-size companies. As 
Table 4 Federal contractors, implementation of disability inclusion practice, and utilization rate

\begin{tabular}{llll}
\hline Outcome measure & $\begin{array}{l}\text { Non-federal contractor } \\
M(S D)\end{array}$ & $\begin{array}{l}\text { Federal contractor } \\
M(S D)\end{array}$ & $F(1,464)$ \\
\hline Implementation score & $47.50(11.26)$ & $52.79(7.46)$ & $34.78^{* * *}$ \\
Utilization rate & $2.09 \%(2.32 \%)$ & $3.57 \%(2.15 \%)$ & $50.70^{* * *}$ \\
\hline
\end{tabular}

$* * * p<.001$ expected, the standard deviation for small-size companies is greater than large- and mid-size companies, indicating a large variation among small-size companies in the implementation of disability inclusion practices. Taken together, these results suggest that company size does affect disability inclusion practices, with small companies less likely to implement disability inclusion practices.

One-way ANOVA showed that the effect of company size on employment rates of people with disabilities was also significant, $F(2,461)=40.19, p<.001$. Post hoc analysis using the Tukey HSD test indicated that the mean score for large-size companies $(n=226 ; M=3.53 \%, S D=2.28 \%)$ was significantly higher than mid-size companies $(n=135$; $M=2.81 \%, S D=2.19 \%)$ and small-size companies $(n=103$; $M=1.20 \%, S D=1.93 \%)$. The mean employment score for mid-size companies was also significantly higher than small-size companies. Collectively, these results suggest that company sizes do have an effect on employment rates of people with disabilities, with large-size companies having the highest representation of people with disabilities in their workforces and small companies having the lowest representation.

\section{Fortune 500 Company}

One-way ANOVA showed that the effect of being a Fortune 500 company on disability inclusion practices was significant, $F(1,461)=12.24, p<.001$. The result indicated that the means score for Fortune 500 companies $(n=126$; $M=52.58, S D=7.59$ ) was significantly higher than the mean score for non- Fortune 500 companies $(n=337 ; M=48.96$, $S D=10.61$ ). Fortune 500 companies are more likely to emphasize and implement disability inclusion practices to recruit, hire, and retain people with disabilities in their workforces.

One-way ANOVA also showed that the effect of being a Fortune 500 company on employment rates of people with disabilities was significant, $F(1,461)=52.55, p<.001$. The result indicated that the means score for Fortune 500 companies $(n=126 ; M=4.04 \%, S D=2.11 \%)$ was significantly higher than the mean score for non- Fortune 500 companies $(n=337 ; M=2.34 \%, S D=2.29 \%)$. Fortune 500 companies had significantly higher employment rates of people with disabilities in their workforces than non-Fortune 500 companies.

\section{Federal Contractors}

One-way ANOVA showed that the effect of Federal contract on disability inclusion practices was significant, $F(1$, $464)=34.78, p<.001$. The result indicated that the means score for Federal contractors (Sect. 503 companies; $n=220$; $M=52.79, S D=7.46)$ was significantly higher than the mean score for non-Federal contractors $(n=246 ; M=47.50$, $S D=11.26$ ). Federal contractors are more likely to emphasize and implement disability inclusion practices to include people with disabilities in their workforces.

One-way ANOVA showed that the effect of companies with Federal contracts on employment rates of people with disabilities was significant, $F(1,464)=50.70, p<.001$. The result indicated that the mean score for Federal contractors (Sect. 503 companies) $(n=220 ; M=3.57 \%, S D=2.15 \%)$ was significantly higher than the mean score for non-Federal contractors $(n=246 ; M=2.09 \%, S D=2.32 \%)$. Federal contractors have significantly higher representation of people with disabilities in their workforce than companies without Federal contracts.

\section{Discussion}

The present study examined the relationships between company characteristics, disability inclusion practices, and employment of people with disabilities. For company characteristics, results indicate large- and mid-size companies do have higher disability inclusion practice implementation scores and higher employment rates of people with disabilities in their workforces than small-size companies. We also found that both Fortune 500 companies and Federal contractors have higher implementation scores and representation of people with disabilities in their workforces than non-Fortune 500 companies and non-Federal contractors. Although Federal contractors are required to meet a $7 \%$ utilization goal of people with disabilities in their workforces, in the present study, Fortune 500 companies with $4.04 \%$ utilization rate is appreciably higher than the $3.57 \%$ rate of Federal contractors. In addition, the sizes of companies that receive Federal contracts can vary significantly. In the present study, $61.2 \%$ of the Federal contractors are large-size companies and $38.8 \%$ are small- to mid-size companies. It should be noted that although small-size companies have lower disability 
inclusion practices implementation scores, with an average rate of $1.92 \%$, small-size companies are still a viable option for employment of people with disabilities.

For disability inclusion practices, we found that these practices can be classified into two major domains: leadership/executive management level disability inclusion practices (Level 1) and middle-managers, supervisors, and staff level disability inclusion practices (Level 2). Level 1 practices have higher implementation scores and correlations with utilization rate than Level 2 practices. It represents leadership/executive's commitments and efforts to influence down and across the organization to drive behavior change. It reflects the actions leadership/executive have taken to communicate their strong commitments and provide the infrastructure and resources needed to foster a workplace culture that supports the inclusion of employees with disabilities. Specifically, in successful companies, commitment at the highest level of the organization is communicated clearly to managers, supervisors and coworkers and in the company's website. Leadership sets utilization goals for employment of persons with disabilities at all levels (including senior management) of the organization and assures there is a mechanism (e.g., the Voluntary Self-Identification of Disability Form CC-305 created by the U.S. Department of Labor) in the company's human resources information systems to track the number of people with disabilities working in the organization. Form CC-305 is available from the United States Department of Labor's Office of Federal Contract Compliance Programs website. Senior management is also mandated to conduct an annual review to evaluate disability inclusion efforts and outcome. To encourage unit heads, department heads, and project managers with hiring authority to hire and retain employees with disabilities, successful companies establish an enterprise-wide accommodations budget line item to pay for applicant and employee accommodations. In addition to financial support, successful companies also ascertain the organization has in-house (or contractual) disability management specialists who are knowledgeable and have the expertise to manage issues related to the ADA and job accommodations. Leadership of successful companies also underscores the importance of disability inclusion training (disability inclusion preparedness) for their managers and staff. Findings of Level 1 practices strongly supported the importance of the top down approach to change workplace culture and disability inclusion climate and to foster a welcoming climate for people with disabilities.

Level 2 practices have a focus on execution of disability inclusion practices by mid-level managers and staff to recruit, hire, and retain people with disabilities. For example, practices consist of collecting data and reporting progress toward hiring persons with disabilities to senior management, establishing a paid internship program for high school and college students with disabilities, partnering with state vocational rehabilitation agencies and community-based rehabilitation and health organizations to recruit qualified individuals with disabilities, and developing strategies to attract qualified applications from persons with disabilities. Other practices include presenting disability and employment as a topic in new employee orientation and in diversity and inclusion training and providing disability inclusion training for employees at all levels of the organization to demystify misperceptions about people with disabilities and their health conditions, job performance and social functioning. Interesting, in the demand-side employment literature, inclusion of disability in companies' diversity inclusion policies and procedures is a significant predictor of employment of people with disabilities in the workplace. However, in this study, the correlation between disability inclusion policy and employment of people with disabilities is only 0.17 ( $p<.001$; midway between small to medium effect sizes). There are many disability-inclusion practices with higher correlations with utilization rate than inclusion of disability in diversity inclusion policies and procedures.

Our findings clearly indicate the significant role leadership/senior management play in supporting or hindering the inclusion of people with disabilities in their workplaces, along with their influence on fostering an inviting atmosphere for people with disabilities to perform their jobs successfully in the organization. It underscores the importance of finding effective ways to connect with leadership/senior executives in order to promote employment opportunities for people with disabilities.

\section{Implications for Disability Services Providers}

People with disabilities have a human right to work [36]. The positive effects of gainful employment on the health and well-being of people with disabilities are well documented $[2,5]$. However, the employment rate of people with disabilities is low compared to people without disabilities, making them vulnerable to the negative consequences of unemployment and poverty [8]. It is alarming that in 2019, when the United States' economy was approaching full employment and managers were reporting a high demand for workers, employers were still not hiring large numbers of people with disabilities [17]. With the COVID-19 pandemic, the U. S. economy is entering another recession [19]. When the supply of workers is higher than the demand for workers, employers will be even more reluctant to hire people with disabilities.

Transition specialists, VR counselors, and other disability services providers must use innovative strategies to identify employers who have a high propensity to hire people with disabilities and redouble their efforts to connect 
and cooperate with employers to identify types of workers and job positions they need to fill and provide appropriate training for their clients to fill those positions. In the current study, large companies, Fortune 500 companies, and Federal contractors were most receptive to hiring people with disabilities. Leadership and district managers in state vocational rehabilitation agencies need to build relationships with senior executives of these types of companies to influence their attitudes toward hiring people with disabilities. A good working relationship between leaders in state vocational rehabilitation agencies and leaders in business organizations can create opportunities for rehabilitation counselors, transition specialists and other disability services providers/vendors to connect with business leaders. In turn, transition specialists, rehabilitation counselors, and other disability service providers also need to increase their employer engagement efforts by developing working relationships with companies that are active in the US Business Leadership Network (USBLN), Society for Human Resource Management (SHRM), the ADA regional centers, and Chamber of Commerce organizations in their communities. The Disability Inclusion Profiler used in this study can be a useful tool for vocational rehabilitation professionals to initiate relationships with local companies by helping employers assess workplace culture and disability inclusion climate and provide disability inclusion training for their employees without disabilities and workplace support for employees with disabilities.

Previous demand-side employment research revealed that countries that use an employment quota system (e.g., Germany, France, and Japan) tend to have smaller disability employment gaps (i.e., the difference between employment rates of people without disabilities and people with disabilities) than countries that use anti-discrimination legislation (e.g., the United Kingdom and the United States; [37]). Federal contractors in the United States are expected to meet the utilization goal of $7 \%$ of people with disabilities in their workforces [30]. For Federal contractors who fail to meet the $7 \%$ aspiration goal, they must take steps to determine whether and where impediments to equal employment exist. This includes assessing existing personnel processes, the effectiveness of its outreach and recruitment efforts, the results of its affirmative action program audit, and any other areas that might affect the success of the affirmative action program. After conducting this assessment, the contractor must develop and execute action-oriented programs to correct any identified problem areas [30]. Rehabilitation counselors, transition specialists and other disability services providers should focus on identifying Federal contractors who are not meeting the $7 \%$ utilization rate and offer to provide technical assistance to increase the pool of qualified workers with disabilities in these companies.

\section{Limitations}

The sample size $(N=446)$ for the present study is relatively large. Although there is evidence to support the use of Amazon's Mechanical Turk for data collection [33, 34], there are studies that caution about the reliability and quality of the research data collected by this method [38]. Additional research using contact lists from the Society for Human Resource Management (SHRM) and lists of Federal contractors purchased from the Office of Federal Contract Compliance Programs is warranted. In addition, a review of the disability inclusion practice ratings suggests that there may be two levels of practices. This is the first time the Disability Inclusion Profiler has been used, and further psychometric testing is warranted.

\section{Conclusions}

The current study evaluated the relationship between company characteristics, disability inclusion practices, and employment rates of people with disabilities. Results indicate large and mid-sized companies, Fortune 500 companies, and Federal contractors are most likely to hire people with disabilities in their workforces. Disability inclusion practices can be divided into those requiring leadership/executive management commitments and efforts to drive behavioral change down and across the organization, and those that are implemented by mid-level managers, supervisors, and staff to recruit, hire, and retain people with disabilities. The top down approach is vitally important for changing workplace culture and climate to support the inclusion of people with disabilities in the workplace. These findings can be used by transition specialists, rehabilitation counselors, and other disability service providers to engage and connect with employers for the purpose of increasing employment opportunity for people with disabilities in the post COVID19 economy.

Acknowledgements The contents of the journal publication were developed under a grant from the National Institute on Disability, Independent Living, and Rehabilitation Research (NIDILRR grant number 90RT5041). NIDILRR is a Center within the Administration for Community Living (ACL), Department of Health and Human Services (HHS). The contents of this journal article do not necessarily represent the policy of NIDILRR, ACL, or HHS, and you should not assume endorsement by the Federal Government.

Funding This study was funded by the National Institute on Disability, Independent Living, and Rehabilitation Research (NIDILRR grant number 90RT5041).

Data Availability The datasets generated during and/or analyzed during the current study are not publicly available due to that we obtained 
informed consents from our participants on the condition that we use the obtained data for this study purpose but are available from the corresponding author on reasonable request.

\section{Compliance with Ethical Standards}

Conflict of interest The authors declare that they have no conflict of interest.

Ethical Approval All procedures performed in studies involving human participants were in accordance with the ethical standards of the institutional and/or national research committee and with the 1964 Helsinki declaration and its later amendments or comparable ethical standards.

Informed Consent Informed consent was obtained from all individual participants included in the study.

\section{References}

1. Fryers T. Work, identity and health. Clin Pract Epidemiol Ment Health. 2006;2(12):1-7.

2. Hall JP, Kurth NK, Hunt SL. Employment as a health determinant for working-age, dually-eligible people with disabilities. Disability Health J. 2013;6(2):100-106.

3. Helliwell JF, Layard R, Sachs JD, De Neve J. World happiness report $2020 ; 2020$. https://happiness-report.s3.amazonaws. com/2020/WHR20.pdf.

4. Ipsen C. Health, secondary conditions, and employment outcomes for adults with disabilities. J Disability Policy Stud. 2006;17(2):77-87.

5. Muller V, Peebles MC, Chiu CY, Iwanaga K, Tang X, Brooks J, Eagle D, Chan F. Association of employment and health and wellbeing in people with fibromyalgia. J Rehabil. 2017;83(3):37-43.

6. Ryckman RM. Theories of personality. Belmont: Cengage Learning; 2012.

7. Kamerāde D, Wang S, Burchell B, Balderson SU, Coutts A. A shorter working week for everyone: how much paid work is needed for mental health and well-being? Soc Sci Med. 2019;241:112353.

8. Driscoll AK, Bernstein AB. Health and access to care among employed and unemployed adults: United States, 2009-2010. Washington: US Department of Health and Human Services, Centers for Disease Control and Prevention, National Center for Health Statistics; 2012.

9. Linn MW, Sandifer R, Stein S. Effects of unemployment on mental and physical health. Am J Public Health. 1985;75(5):502-506.

10. McKee-Ryan F, Song Z, Wanberg CR, Kinicki AJ. Psychological and physical well-being during unemployment: a meta-analytic study. J Appl Psychol. 2005;90(1):53-76.

11. Livneh H, Chan F, Kaya C. Stigma related to physical and sensory disabilities. In: Corrigan PW, editor. The stigma of disease and disability: understanding causes and overcoming injustices. Washington: American Psychological Association; 2014. p. 93-120.

12. World Health Organization. World report on disability: Summary. Geneva, Switzerland: World Health Organization; 2011. http:// whqlibdoc.who.int/hq/2011/WHO_NMH_VIP_11.01_eng.pdf.

13. Yaghmaian R, Iwanaga K, Wu JR, Chen X, Umucu E, Tao J, Livneh H, Chan F. Reducing prejudice toward people with disabilities. In: Dunn D, editor. Disability: social psychological perspectives. New York: Oxford University Press; 2019. pp. 52-73.
14. Fogg NP, Harrington PE, McMahon BT. The impact of the Great Recession upon the unemployment of Americans with disabilities. J Vocat Rehabil. 2010;33(3):193-202.

15. Fontanari C, Palumbo A, Salvatori C. Is it really "Full Employment"? Margins for expansion in the US economy in the middle of 2019. New York, NY: Institute for New Economic Thinking; 2019. https://www.ineteconomics.org/perspectives/blog/is-it-reall y-full-employment.

16. Long H. U.S. unemployment fell to 3.6 percent, lowest since 1969. Washington D.C.: The Washington Post; 2019. https://www. washingtonpost.com/business/2019/05/03/us-economy-added -jobs-april-unemployment-fell-percent-lowest-since/.

17. National Organization on Disability. New employer survey reveals corporate America still struggling to hire people with disabilities. Washington, DC: National Organization on Disability; 2019. https ://www.nod.org/new-employer-survey-reveals-corporate-americastill-struggling-to-hire-people-with-disabilities/.

18. Frankel J. The United States is officially in recession thanks to the coronavirus crisis. The Guardian; 2020. https://www.theguardia n.com/business/2020/june/16/us-recession-coronavirus-crisis.

19. Kessler Foundation and the University of New Hampshire. (2020). nTIDE September 2020 Jobs Report. https://researchondisability .org/home/ntide/ntide-news-item/2020/10/02/ntide-september2020-jobs-report-unease-rises-as-numbers-fall-for-americanswith-disabilities. Accessed 10 Oct 2020.

20. U.S. Department of Labor, Office of Disability Employment Policy. Disability statistics. https://www.dol.gov/agencies/odep. Accessed 10 Oct 2020.

21. Gilbride D, Stensrud R, Vandergoot D, Golden K. Identification of the characteristics of work environments and employers open to hiring and accommodating people with disabilities. Rehabil Couns Bull. 2003;46(3):130-137.

22. Chan F, Strauser D, Maher P, Lee EJ, Jones R, Johnson ET. Demand-side factors related to employment of people with disabilities: a survey of employers in the Midwest region of the United States. J Occup Rehabil. 2010;20(4):412-419.

23. Habeck R, Hunt A, Rachel CH, Kregel J, Chan F. Employee retention and integrated disability management practices as demand side factors. J Occup Rehabil. 2010;20(4):443-455.

24. Bezyak J, Moser E, Iwanaga K, Wu JR, Chen X, Chan F. Disability inclusion strategies: an exploratory study. J Vocat Rehabil. 2020.

25. Iwanaga K, Chen X, Wu JR, Lee B, Chan F, Bezyak J, Grenawalt TA, Tansey TN. Assessing disability inclusion climate in the workplace: a brief report. J Vocat Rehabil. 2018;49(2):265-271.

26. Fraser R, Ajzen I, Johnson K, Hebert J, Chan F. Understanding employers' hiring intention in relation to qualified workers with disabilities. J Vocat Rehabil. 2011;35(1):1-11.

27. Fraser RT, Johnson K, Hebert J, Ajzen I, Copeland J, Brown P, Chan F. Understanding employers' hiring intentions in relation to qualified workers with disabilities: preliminary findings. J Occup Rehabil. 2010;20(4):420-426.

28. Organization for Economic Co-operation and. Development OCED. OCED data: Enterprises by business size. OECD; 2020. https://data.oecd.org/entrepreneur/enterprises-by-business-size. htm.

29. Fortune. Fortune 500; 2020. https://fortune.com/fortune500/.

30. U. S. Department of Labor. Factsheet: The Workforce Innovation and Opportunity Act; 2014. Ahttps://wdr.doleta.gov/directives/ attach/TEN/WIOA_Factsheet_Acc.pdf.

31. Chan F, Tansey TN, Iwanaga K. Disability Inclusion Profiler. Madison WI. 2019. University of Wisconsin-Madison, Rehabilitation and Research Training Center-Employer Practices.

32. Crocker L, Algina J. Introduction to classic and modern test theory. Belmont: Wadsworth Publishing Company; 2006. 
33. Litman L, Robinson J, Abberbock T. TurkPrime. com: a versatile crowdsourcing data acquisition platform for the behavioral sciences. Behav Res Methods. 2017;49(2):433-442.

34. Sheehan KB. Crowdsourcing research: data collection with Amazon's Mechanical Turk. Commun Monogr. 2018;85(1):140-156.

35. Cohen J. A power primer. Psychol Bull. 1992;112(1):155-159.

36. Office of the United Nations High Commissioner for Human Rights. Questionnaire. "The right to work" Response of Ireland. United Nations Human Rights Office of the High Commissioner; 2018. https://www.ohchr.org/_layouts/15/WopiFrame.aspx?sourc edoc=/Documents/Issues/ESCR/Youth/Ireland.docx\&actio $\mathrm{n}=$ default $\&$ DefaultItemOpen $=1$.
37. Iwanaga K, Chan F, Chen X, Lee B, Grenawalt TA, Wu JR, Mpofu $\mathrm{N}$, Tansey T. Factors influencing employers' motivation to recruit and hire people with disabilities: a scoping review. J Rehabil. 2020.

38. Rouse SV. A reliability analysis of Mechanical Turk data. Comput Hum Behav. 2015;43:304-307.

Publisher's Note Springer Nature remains neutral with regard to jurisdictional claims in published maps and institutional affiliations. 